\title{
20(S)-Protopanaxadiol induces apoptosis in human hepatoblastoma HepG2 cells by downregulating the protein kinase $B$ signaling pathway
}

\author{
ZEYUAN LU* , HUALI XU* ${ }^{*}$ XIAOFENG YU, YUCHEN WANG, LONG HUANG, XIN JIN and DAYUN SUI \\ Department of Pharmacology, School of Pharmaceutical Sciences, Jilin University, Changchun, Jilin 130021, P.R. China
}

Received May 22, 2017; Accepted October 26, 2017

DOI: $10.3892 /$ etm.2017.5594

\begin{abstract}
Hepatoblastoma is the most common primary liver tumor for children aged $<5$ years old. 20(S)-Protopanaxadiol (PPD) is a ginsenoside extracted from Pananx quinquefolium $L$., which inhibits tumor growth in several cancer cell lines. The purpose of the present study was to assess the anticancer activities of 20(S)-PPD in human hepatoblastoma HepG2 cells. The cytotoxicity of 20(S)-PPD on HepG2 cells was evaluated using an MTT assay. Apoptosis was detected using DAPI staining and flow cytometry. The expression of apoptosis-associated proteins was identified by western blotting. The results demonstrated that 20(S)-PPD inhibited the viability of HepG2 cell in a dose and time-dependent manner. The $\mathrm{IC}_{50}$ values were $81.35,73.5,48.79 \mu \mathrm{M}$ at 24,48 and $72 \mathrm{~h}$, respectively. Topical morphological changes of apoptotic body formation following 20(S)-PPD treatment were detected by DAPI staining. The percentage of Annexin V-fluoroscein isothyiocyanate positive cells were $3.73,17.61,23.44$ and $65.43 \%$ in HepG2 cells treated with $0,40,50$ and $60 \mu \mathrm{M}$ of 20(S)-PPD, respectively. Furthermore, 20(S)-PPD upregulated the expression of Bax and downregulated the expression of $\mathrm{Bcl}-2$ and also activated caspases-3 and -9 , and Poly [ADP-ribose] polymerase cleavage. In addition, 20(S)-PPD inhibited the phosphorylation of protein kinase B (Akt; Ser473). The results indicate that $20(\mathrm{~S})$-PPD inhibits the viability of HepG2 cells and induces apoptosis in HepG2 cells by inhibiting the phosphoinositide-3-kinase/Akt pathway.
\end{abstract}

Correspondence to: Dr Dayun Sui, Department of Pharmacology, School of Pharmaceutical Sciences, Jilin University, 1266 Fujin Road, Changchun, Jilin 13 0021, P.R. China

E-mail: suidy@jlu.edu.cn

*Contributed equally

Key words: 20(S)-Protopanaxadiol, apoptosis, caspase, ginsenoside, hepatoblastoma cell HepG2

\section{Introduction}

Hepatoblastoma is the most common primary liver tumor in children aged $<5$ years old (1). It primarily affects males and is rarely present in adults (2), and accounts for $80 \%$ of all liver tumors in children (3). In the 1970s, surgical resection was the primary method used to treat hepatoblastoma; however, complete removal of tumor was often unsuccessful and tumor metastasis often occurred (4). Currently, surgery with neoadjuvant chemotherapy is used to treat hepatoblastoma (5). It has been reported that chemotherapy causes $\sim 90 \%$ of hepatoblastomas to shrink and also inhibits tumor growth (6). However, the chemotherapy drugs commonly used for neoadjuvant chemotherapy, including cisplatin and doxorubicin, induce certain cytotoxic effects and may cause neutropenia $(7,8)$. Thus, a novel effective chemotherapy drug to treat hepatoblastoma is required.

Apoptosis serves an important role in stabilizing the internal environment (9). Under normal conditions, cellular apoptosis is tightly regulated to maintain the stability of tissues and organs. An imbalance of apoptosis can lead to the overgrowth of cells or excessive cell death (10). Thus, apoptosis is an important pathway that leads to cell death (11). It has been demonstrated that the apoptotic pathway includes the Fas-FasL, mitochondrial and endoplasmic reticulum stress pathways (12-14) and the induction of apoptosis is a common clinical strategy used to treat cancer $(15,16)$. A large number of drugs, including paclitaxel, chidamide and dihydromyricetin, induce the apoptosis of cancer cells by targeting different pathways (17-19). However, natural medicines or their modified products are being increasingly investigated for their ability to treat patients with cancer.

20(S)-Protopanaxadiol (PPD; Fig. 1) is an active ginseng metabolite and is the final form of protopanaxadiol saponins metabolized by human intestinal microflora (20). 20(S)-PPD exhibits various effects, including antidepressant, antioxidant and anti-fatigue effects (21-24). It has been demonstrated as a potent cytotoxic agent in vitro in human cancer cell lines, including the human breast cancer cell line MCF-7, the human lung adenocarcinoma cell line A549 and the human prostate cancer cell line LNCaP (25-28). One of the mechanisms of 20(S)-PPD's cytotoxic effect is to induce apoptosis (25). However, to the best of our knowledge, the mechanism by which 20(S)-PPD induces cytotoxicity in hepatoblastoma 
has not yet been determined. Therefore, the current study investigated the cytotoxic mechanism of 20(S)-PPD in hepatoblastoma HepG2 cells.

\section{Materials and methods}

Cell culture and reagents. Human hepatoblastoma HepG2 cells were obtained from the Shanghai Institute of Cell Biology, Chinese Academy of Sciences (Shanghai, China). HepG2 cells were cultured in RPMI-1640 (Gibco; Thermo Fisher Scientific; Waltham; MA; USA) with $10 \%$ fetal bovine serum (Zhejiang Tianhang Biotechnology Co., Ltd., Huzhou, China). 20(S)-PPD was provided by Hainan Asia Pharmaceutical Co. Ltd., (Hainan, China). The purity of 20(S)-PPD used in experiments was $>95 \%$, as determined by high performance liquid chromatography (Agilent 1100), with a Zoebax Extent $\mathrm{C}_{18}$ column (250x4.6 mm, $5 \mu \mathrm{m}$ ) (both, Agilent Technologies, Inc., Santa Clara, CA, USA) at $25^{\circ} \mathrm{C}$, methanol and water (90:10) was used as the mobile phase, the flow rate was $1.2 \mathrm{ml} / \mathrm{min}$ and the sample quantity was $10 \mu \mathrm{l}$ ). The DAPI staining and caspase activity assay kits were purchased from Beyotime Institute of Biotechnology (Haimen, China). An Annexin V-FITC apoptosis detection kit was obtained from Tianjin Sungene Biotech Co., Ltd. (Tianjin, China). MTT and all other reagents were purchased from Sigma-Aldrich; Merck KGaA (Darmstadt, Germany). The primary antibodies against cleaved caspase-3 and cleaved caspase-9, poly (ADP-ribose) polymerase (PARP), cleaved-PARP (also detected by the primary PARP antibody), Bcl-2, Bax and Phospho-Akt Pathway Antibody Sampler kit were purchased from Cell Signaling Technology, Inc. (Danvers, MA, USA). The primary antibody against $\beta$-actin was purchased from Beijing Zhongshan Jinqiao Biotechnology Co., Ltd. (Beijing, China). The goat-anti-mouse secondary and goat-anti-rabbit secondary antibodies were purchased from Beijing Dingguo Changsheng Biotechnology Co., Ltd. (Beijing, China).

Cell treatment. Cells were treated with different concentrations of 20(S)-PPD $(6.25,12.5,25,50$ and $100 \mu \mathrm{M})$ in an MTT assay. Cells were administered with 40, 50 and $60 \mu \mathrm{M}$ 20(S)-PPD prior to DAPI staining, flow cytometry and western blot analysis. Equal volumes of 10\% FBS 1640 medium without 20(S)-PPD was used for the control group.

MTT assay. The HepG2 cell line was plated in 96-well plates $\left(5 \times 10^{4} / \mathrm{ml}\right)$ and incubated with RPMI-1640 medium containing $10 \% \mathrm{FBS}$ for $24 \mathrm{~h}$, at $37^{\circ} \mathrm{C}$. Cells were then treated with different concentrations of 20(S)-PPD (6.25, $12.5,25,50$ and $100 \mu \mathrm{M})$, control group cells were treated with equal volume RPMI-1640 medium containing $10 \%$ FBS. Following incubation for 20,44 and $68 \mathrm{~h}$ at $37^{\circ} \mathrm{C}, 10 \mu \mathrm{l}$ MTT solution $(5 \mathrm{mg} / \mathrm{ml}$ in PBS) was added to each well and the each plate was incubated for a further $4 \mathrm{~h}$ at $37^{\circ} \mathrm{C}$. The medium was removed from each well, crystals were resolved with dimethyl sulfoxide and the plate was shaken for $10 \mathrm{~min}$ to mix. Absorbance was read at $570 \mathrm{~nm}$ with using a microplate reader (SpectraMax Plus 384; Molecular Devices, LLC, Sunnyvale, CA, USA). Cell viability was determined by the ratio of treatment group/control group. The half-maximal inhibitory concentration $\left(\mathrm{IC}_{50}\right)$ was calculated from the dose-response curve using Origin 8.0 software (Origin Lab Corporation, Northampton, MA, USA).

DAPI staining. HepG2 cells $\left(4 \times 10^{5} / \mathrm{ml}\right)$ were seeded on coverslips with 40,50 and $60 \mu \mathrm{M} 20$ (S)-PPD for $24 \mathrm{~h}$ at $37^{\circ} \mathrm{C}, 10 \%$ FSB 1640 medium was used for the control group. Coverslips were washed twice with PBS, fixed in $4 \%$ paraformaldehyde for $30 \mathrm{~min}$ at room temperature. permeabilized with $0.1 \%$ Triton X-100 and stained with $2 \mu \mathrm{g} / \mathrm{ml}$ DAPI for $10 \mathrm{~min}$ at room temperature. Cells were then observed under a fluorescence microscope (Nikon TE-2000U; Nikon Corporation, Tokyo, Japan).

Flow cytometry. Apoptosis induced by 20(S)-PPD in HepG2 cells was quantified by staining with Annexin V-fluorescein isothiocyanate (FITC)/propidium iodide (PI). Following 20(S)-PPD treatment, HepG2 cells were collected and washed twice in ice cold PBS. Cells were then resuspended in $300 \mu 1$ binding buffer containing $1 \mu \mathrm{g} / \mathrm{ml}$ PI and $0.05 \mu \mathrm{g} / \mathrm{ml}$ Annexin V-FITC. Samples were incubated for $15 \mathrm{~min}$ at room temperature in the dark and analyzed using a flow cytometer and CellQuest ${ }^{\mathrm{TM}}$ Pro (version 6.0) software (BD Biosciences, Franklin Lakes, NJ, USA).

Western blot analysis. Following treatment with different concentrations (40,50 and $60 \mu \mathrm{M})$ of 20(S)-PPD, protein from HepG2 cells was extracted by a radioimmunoprecipitation assay buffer containing 1\% phenylmethane sulfonyl fluoride (both Beijing Dingguo Changsheng Biotechnology Co., Ltd.), then proteins were determined using a BCA protein assay kit. Proteins (20 $\mu \mathrm{g} / \mathrm{lane})$ were then loaded onto a $12 \%$ polyacrylamide-SDS gel. The gel was subsequently blotted onto a PVDF membrane and blocked with 5\% (w/v) non-fat milk for $1 \mathrm{~h}$ at room temperature. The membrane was then incubated with cleaved caspase-3 (cat. no. 9664S), cleaved caspase-9 (cat. no. 7237T), PARP (cat. no. 9532T), Bcl-2 (cat. no. 4223T), Bax (cat. no. 5023T), Akt and p-Akt (Ser 473) were from the Phospho-Akt Pathway Antibody Sampler kit (cat. no. 9916T) and $\beta$-actin (cat. no. TA-09) primary antibodies at 1:1,000 dilutions at $4^{\circ} \mathrm{C}$ overnight. Primary antibody binding was detected using a secondary antibody conjugated to horseradish peroxidase The goat-anti-mouse (cat. no. IH-0031) and goat-anti-rabbit (cat. no. IH-0011) secondary antibodies were used at 1:5,000 dilution at room temperature for $1 \mathrm{~h}$, and visualized using a BeyoECL Plus enhanced chemiluminescence kit (Beyotime Institute of Biotechnology) ImageJ software (version 1.5.0.26; National Institutes of Health, Bethesda, MD, USA) was used for analysis.

Statistical analysis. The results are expressed as mean \pm standard deviation of three independent experiments. Statistical differences were evaluated using a Student's test or one-way analysis of variance with Tukey's post hoc test. $\mathrm{P}<0.05$ was determined to indicate statistically significant differences.

\section{Results}

Effect of 20(S)-PPD on HepG2 cell viability. Different concentrations of 20(S)-PPD $(6.25,12.5,25,50$ or $100 \mu \mathrm{M})$ were administered to HepG2 cells for 24,48 and 72 h. It was 


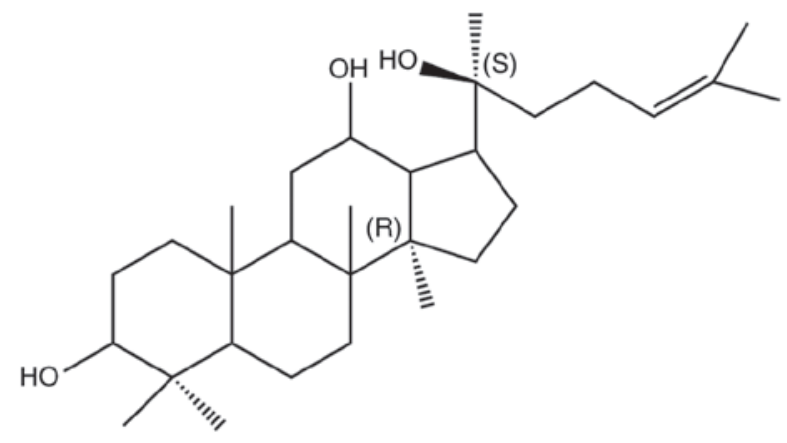

Figure 1. Chemical structure of 20(S)-Protopanaxadiol.

observed that the viability of HepG2 cells was decreased in a dose-dependent manner with increasing concentrations of 20(S)-PPD (Fig. 2). This was clearest at 72 h. There was a significant reduction in cell viability at $6.25 \mu \mathrm{M} 20(\mathrm{~S})$-PPD at $24(94.10 \pm 2.031 \%)$ and $48 \mathrm{~h}(89.66 \pm 2.546 \%)$ compared with the control group. A significantly inhibition of cell viability was observed at $50 \mu \mathrm{M} 20$ (S)-PPD at $24(87.03 \pm 2.257 \%)$, $48(72.55 \pm 3.304 \%)$ and $72 \mathrm{~h}(45.99 \pm 5.546 \%)$. These results indicate that 20(S)-PPD inhibited the viability of HepG2 cells in a dose- and time-dependent manner (Fig. 2). The $\mathrm{IC}_{50}$ values were calculated as 81.35, 73.5, 48.79 $\mu \mathrm{M}$ in HepG2 cells at 24, 48 and $72 \mathrm{~h}$ by Origin 8.0. According to the $\mathrm{IC}_{50}$ values and morphology change of HepG2 the doses of 40,50 and $60 \mu \mathrm{M}$ 20(S)-PPD were selected for subsequent studies.

Effects of 20(S)-PPD on HepG2 cell apoptosis. The present study attempted to elucidate whether the decrease in HepG2 cell viability induced by 20(S)-PPD was associated with apoptosis; therefore, morphological changes were identified using DAPI staining. The number of apoptotic bodies observed in the 20(S)-PPD treatment groups were markedly increased compared with the control group (Fig. 3). Apoptotic cells exhibit typical changes, including shrinkage, chromatin condensation and karyorrhexis $(29,30)$.

Furthermore, the number of apoptotic bodies in the 20(S)-PPD treatment groups increased in a dose-dependent manner. The apoptosis rate induced by 20(S)-PPD was quantified using an Annexin V-FITC/PI assay. The proportion of Annexin V-FITC positive cells in the control group and 40, 50, $60 \mu \mathrm{M}$ 20(S)-PPD treatment groups were 3.73, 17.61, 23.44 and $65.43 \%$, respectively (Fig. 4).

Effects of 20(S)-PPD on apoptosis-associated proteins in HepG 2 cells. The expression of cleaved caspase-3 and -9 were significantly increased in HepG2 cells following 20(S)-PPD treatment compared with the control group (all $\mathrm{P}<0.05$; Fig. 5). Cleaved PARP expression was also measured following 20(S)-PPD treatment. PARP is a substrate of caspase-3. The cleaved PARP was also increased and this revealed that 20(S)-PPD activated caspase-3 in HepG2 cells.

The expression of the apoptosis associated proteins Bcl-2 and Bax was also measured. Compared with the control group, Bcl-2 expression was significantly decreased following treatment with 50 and $60 \mu \mathrm{M}$ 20(S)-PPD, whereas the expression of Bax was increased following treatment with 40,50 and $60 \mu \mathrm{M}$ 20(S)-PPD (Fig. 6). Furthermore, the ratio of Bcl-2/Bax was significantly decreased in a dose-dependent manner following treatment with 20(S)-PPD.

Effect of 20(S)-PPD on the Akt pathway in HepG2 cells. The phosphoinositide-3-kinase/protein kinase B (PI3K/Akt) pathway is an anti-apoptotic pathway that confers a survival advantage and resistance in cancer cells to various types of anticancer therapies $(31,32)$. The effect of 20(S)-PPD on the PI3K/Akt pathway was investigated in the current study. The expression of phosphorylated Akt protein (Ser473) was significantly downregulated following treatment with 20(S)-PPD compared with the control; however, there was no effect on the expression of total Akt (Fig. 7).

\section{Discussion}

The results of our previous studies demonstrated that 20(S)-PPD induced apoptosis in MCF-7 cells via the caspase-mediated pathway and triggered apoptosis via the PI3K/Akt pathway in human lung adenocarcinoma A549 cells $(25,26)$. In the present study, the effect of 20(S)-PPD on hepatoblastoma HepG2 cells was evaluated. The results demonstrated that 20(S)-PPD inhibits the viability of HepG2 cells in a dose- and time-dependent manner and that the $\mathrm{IC}_{50}$ values were 81.35, 73.5 and $48.79 \mu \mathrm{M}$, respectively. The morphological characteristics of apoptosis, including the formation of apoptotic bodies, were detected in HepG2 cells treated with 20(S)-PPD. In addition, apoptosis induced by 20(S)-PPD was confirmed by Annexin V-FITC/PI staining. These results suggest that 20(S)-PPD inhibits the viability of HepG2 cells by inducing apoptosis.

Apoptosis is regulated by a series of signaling cascades under certain circumstances, including hypoxia stimulated by reactive oxygen species and DNA damage $(33,34)$. The caspase family serves an important role in the induction, transduction and amplification of intracellular apoptotic signals and the activation of caspase- 3 is an irreversible stage in the mitochondrial pathway of apoptosis $(35,36)$. The mitochondrial pathway serves a central role due to its feedback loop and involvement in the majority of apoptosis pathways (37). In the mitochondrial pathway, the apoptotic protease-activating factor combined with Cytochrome $c$ (Cyt $c$ ) activates caspase-9, which in turn, activates downstream caspase-3 (38). The activation of caspase- 3 induces the cleavage of PARP, a well-known substrate of caspase-3 (25,39). 20(S)-PPD promotes the activation of caspase-3 and caspase-9. In the present study, it was demonstrated that the increase in hydrolyzed PARP emphasized that 20(S)-PPD activated the cleavage of caspase-3 and caspase-9.

B-cell lymphoma-2 is a member of Bcl-2 family and serves a critical role in apoptosis (40). Bcl-2 family proteins are divided into two categories: Apoptosis inhibitors and apoptosis promoters $(41,42)$. It has been demonstrated that $\mathrm{Bcl}-2$ binds with Bax and Bcl-2 homologous antagonist killer (Bak), inhibiting the anti-apoptotic effects of Bax and Bak (43). In the current study, 20(S)-PPD decreased Bcl-2 expression while increasing the expression of Bax, thus decreasing the Bcl-2/Bax ratio.

PI3K signaling serves an important role in cellular physiology and is involved in various physiological processes, 

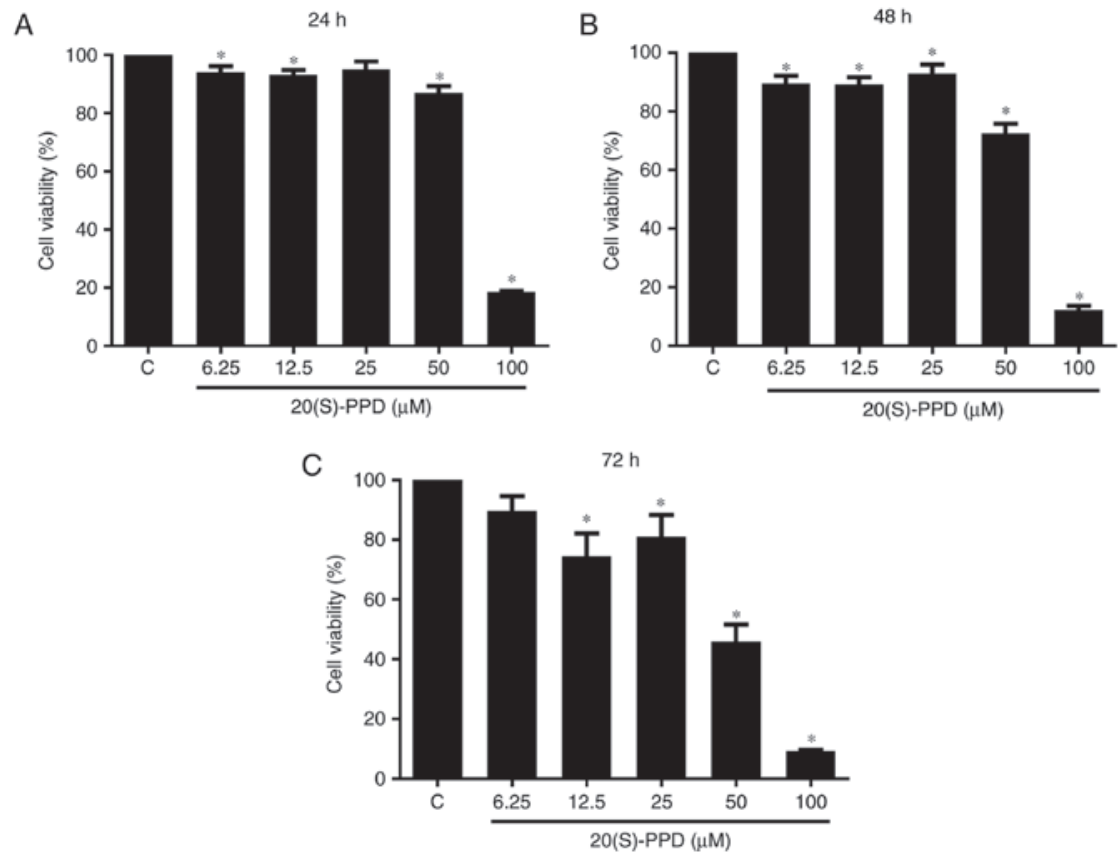

Figure 2. Effect of 20(S)-PPD on HepG2 cell viability. HepG2 cells $\left(5 \times 10^{4} / \mathrm{ml}\right)$ were seeded in 96 -well plates then treated with different concentrations $(6.25,12.5,25,50,100 \mu \mathrm{M})$ of 20(S)-PPD for (A) 24, (B) 48 and (C) $72 \mathrm{~h}$. Cell viability was determined using an MTT assay. Values are expressed as the mean \pm standard deviation of three experiments. ${ }^{*}<<0.05$ vs. the control group. C, control group; 20(S)-PPD, 20(S)-Protopanaxadiol.

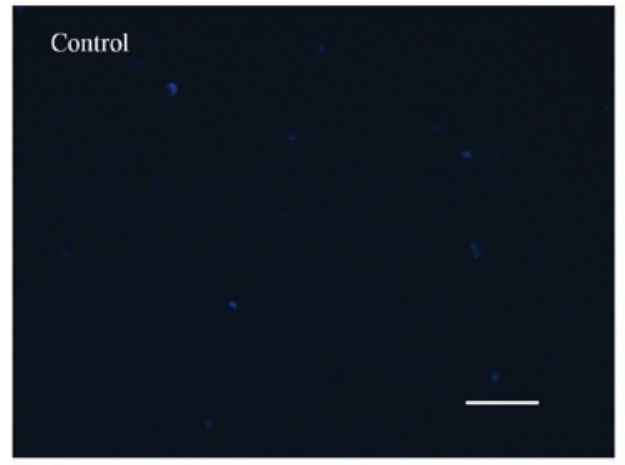

C

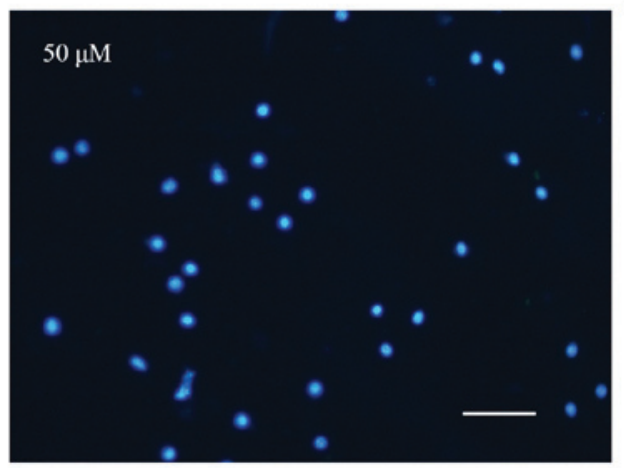

B
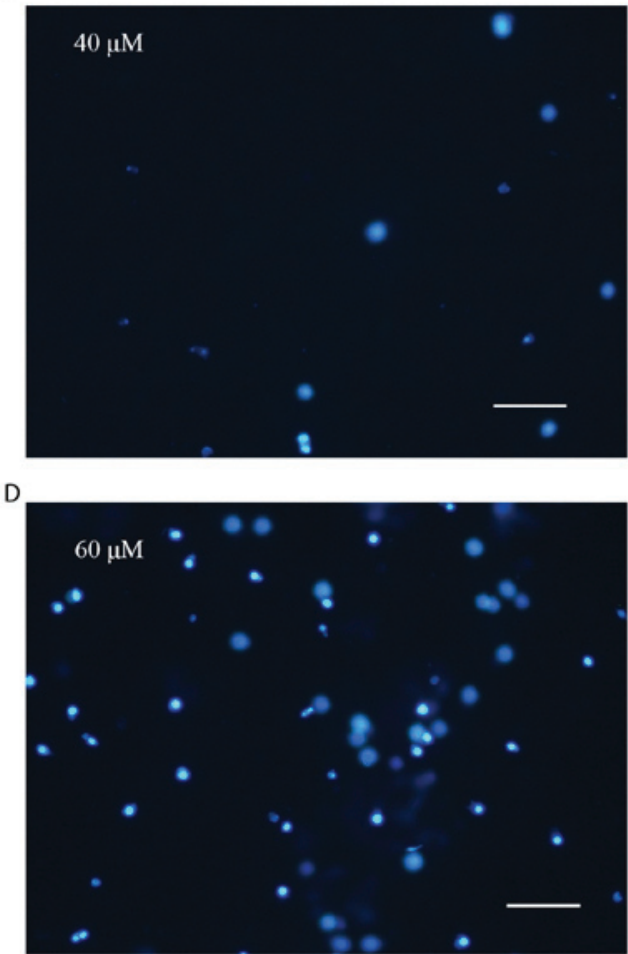

Figure 3. Effect of 20(S)-PPD on morphological changes in HepG2 cells. HepG2 cells (4x105/ml) were treated using (A) 0, (B) 40 , (C) 50 and (D) $60 \mu \mathrm{M}$ 20(S)-PPD for $24 \mathrm{~h}$ and then stained using DAPI. Magnification, x100. Scale Bar, $100 \mu \mathrm{M}$. 20(S)-PPD, 20(S)-Protopanaxadiol.

including cell division, differentiation and apoptosis (44-46). The expression of PI3K is markedly increased in patients with cancer (47). Akt is a serine/threonine protein kinase that is encoded by the proto-oncogene c-Akt (48). The presence of the activating gene locus on Ser473 is necessary to completely activate Akt (49). It has been demonstrated that the regulation of PI3K/Akt signaling leads to the phosphorylation of a series of downstream signals, including proteins from the Bcl-2 and caspase families, leading to the induction of apoptosis (50). The Bcl2-associated agonist of cell death (Bad) 
A

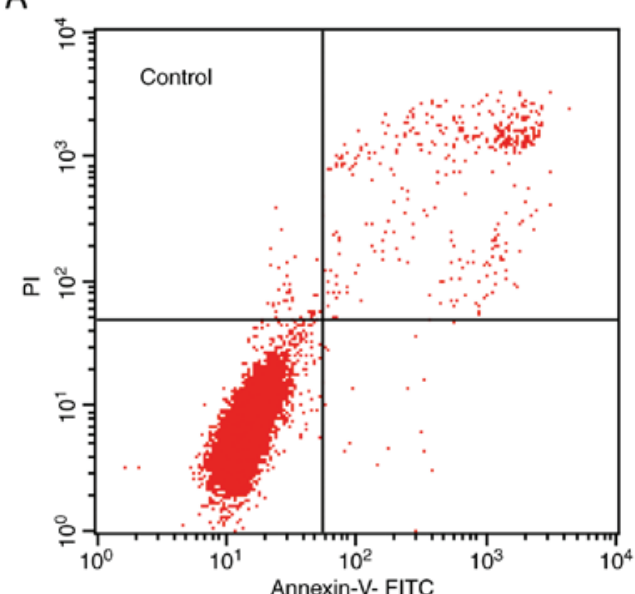

C

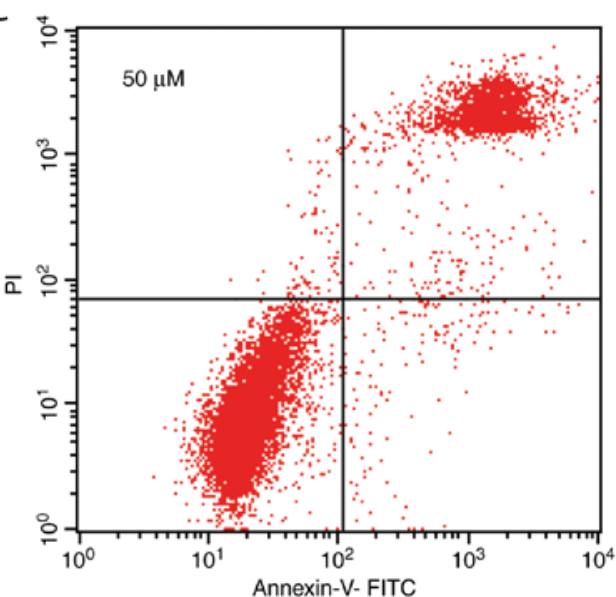

B

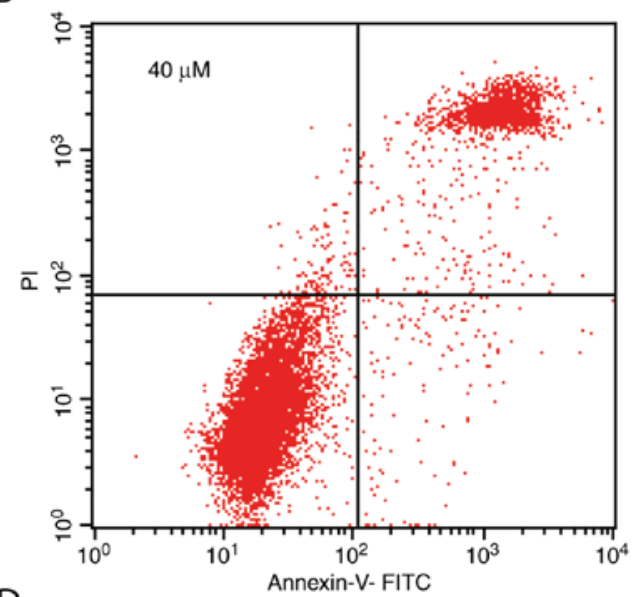

D

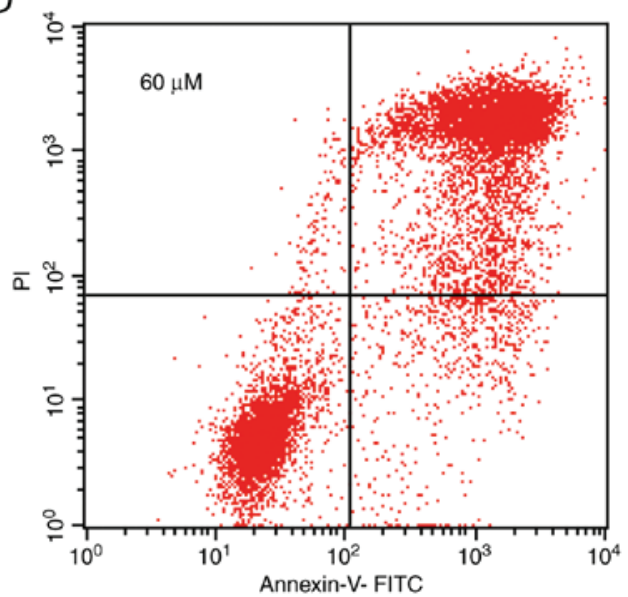

Figure 4. Effect of 20(S)-PPD on HepG2 cell apoptosis. HepG2 cells (4x105 per ml) were treated using (A) 0, (B) 40, (C) 50 and (D) $60 \mu \mathrm{M} 20$ (S)-PPD for $24 \mathrm{~h}$ and were then stained using Annexin V-FITC and PI for flow cytometry analysis. Apoptotic cells were on the top right panels of each image. 20(S)-PPD, 20(S)-Protopanaxadiol; FITC, fluorescein isothiocyanate; PI, propidium iodide.
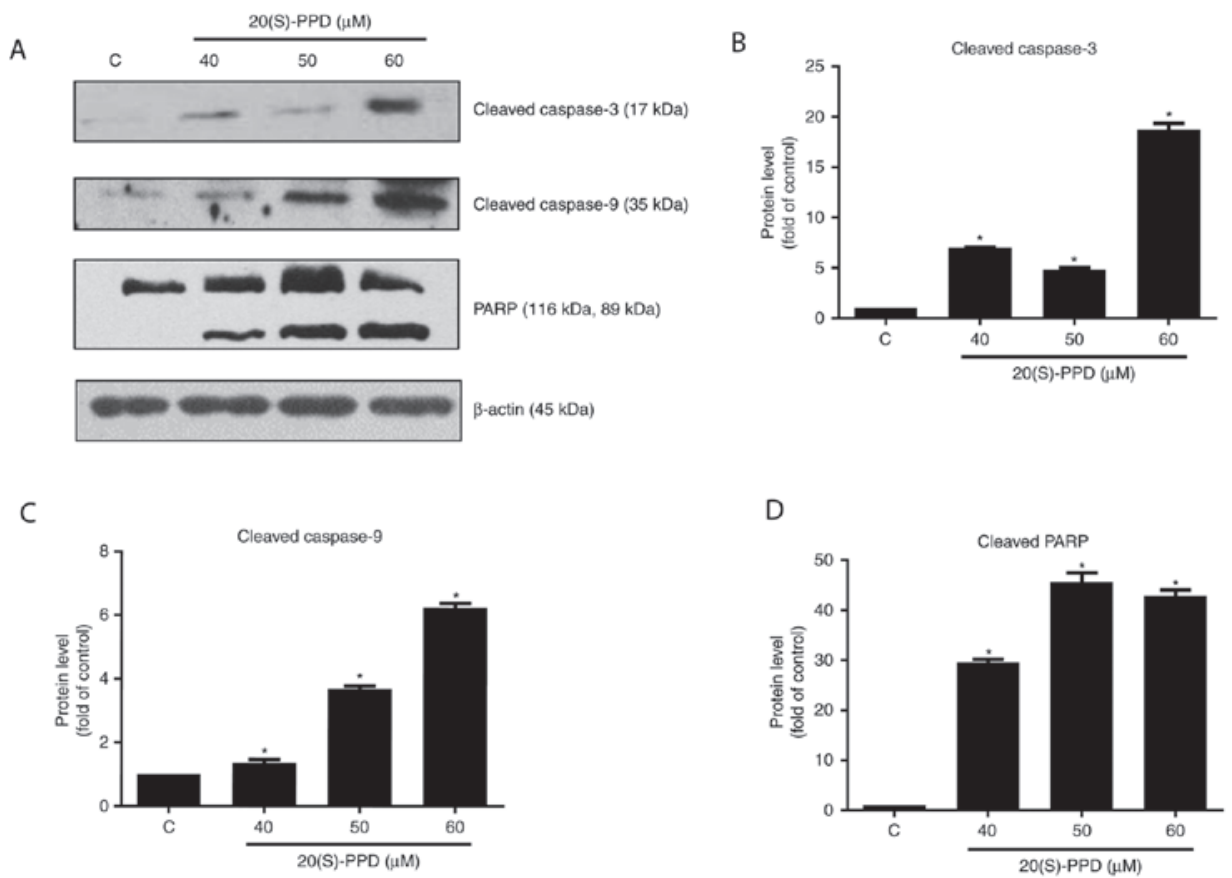

Figure 5. Effect of 20(S)-PPD on apoptosis-associated proteins in HepG2 cells. (A) HepG2 cells ( $4 \times 10^{5}$ per ml) were treated using $0,40,50$ and $60 \mu \mathrm{M}$ of 20(S)-PPD for $24 \mathrm{~h}$ and the expression of cleaved caspase-3, cleaved caspase- 9 and PARP were determined using western blot analysis. Quantification of western blot analysis for (B) cleaved caspase-3, (C) cleaved caspase-9 and (D) PARP (top, $116 \mathrm{kDa}$ ) and cleaved PARP (bottom, $89 \mathrm{kDa}$ ). All values are expressed as the mean \pm standard deviation. "P<0.05 vs. the control group. C, control group; 20(S)-PPD, 20(S)-Protopanaxadiol; PARP, poly (ADP-ribose) polymerase. 

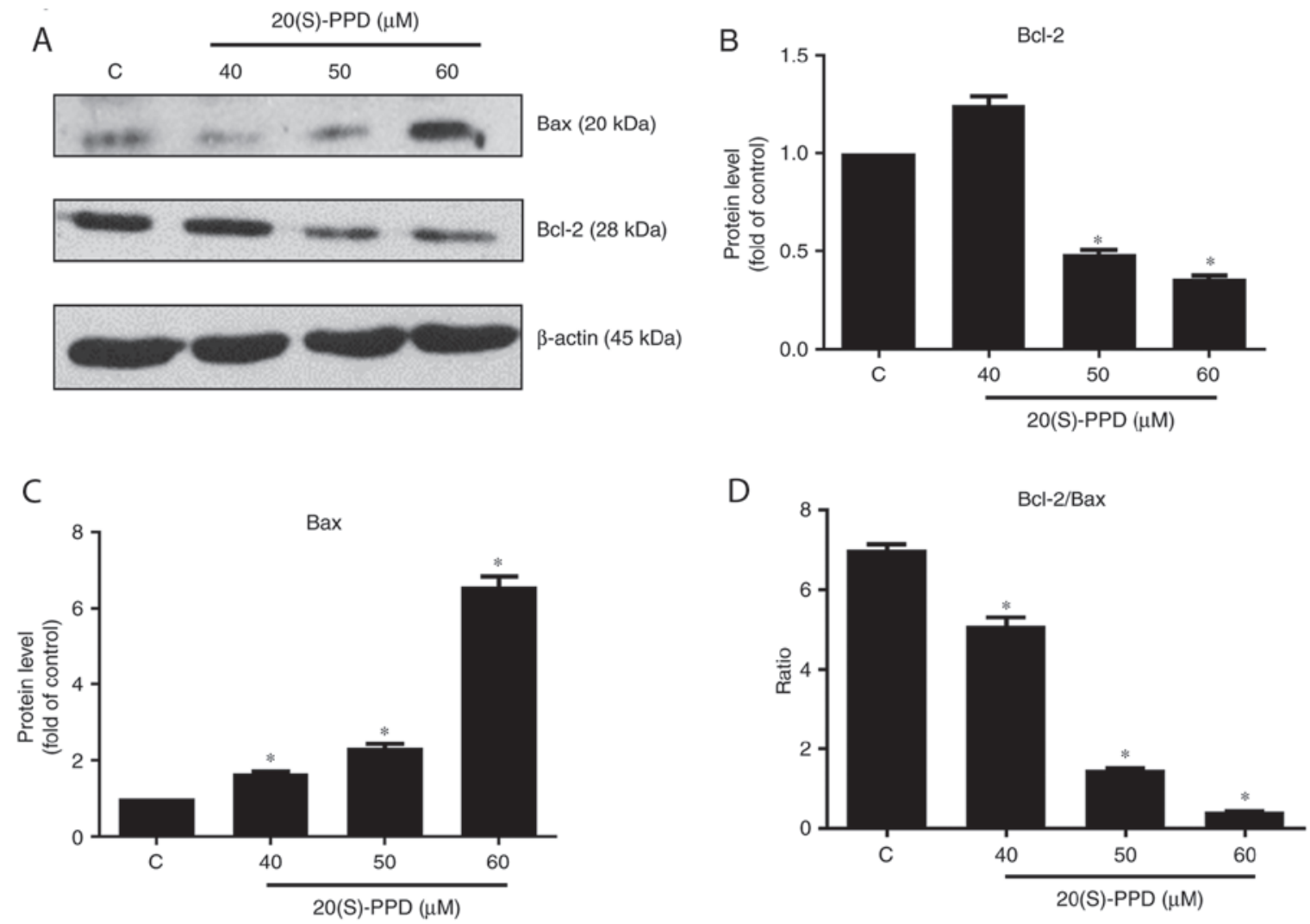

Figure 6. Effect of 20(S)-PPD on the Bcl-2 family in HepG2 cells. (A) HepG2 cells (4x105 per ml) were treated using 0,40, 50 and $60 \mu \mathrm{M}$ of 20 (S)-PPD for $24 \mathrm{~h}$ and the expression of Bcl-2 and Bax were determined using western blotting. Quantification of western blot analysis for (B) Bcl-2, (C) Bax and (D) Bcl-2/Bax. All values are expressed as the mean \pm standard deviation. ${ }^{*} \mathrm{P}<0.05$ vs. the control group. C, control group; 20(S)-PPD, 20(S)-Protopanaxadiol.
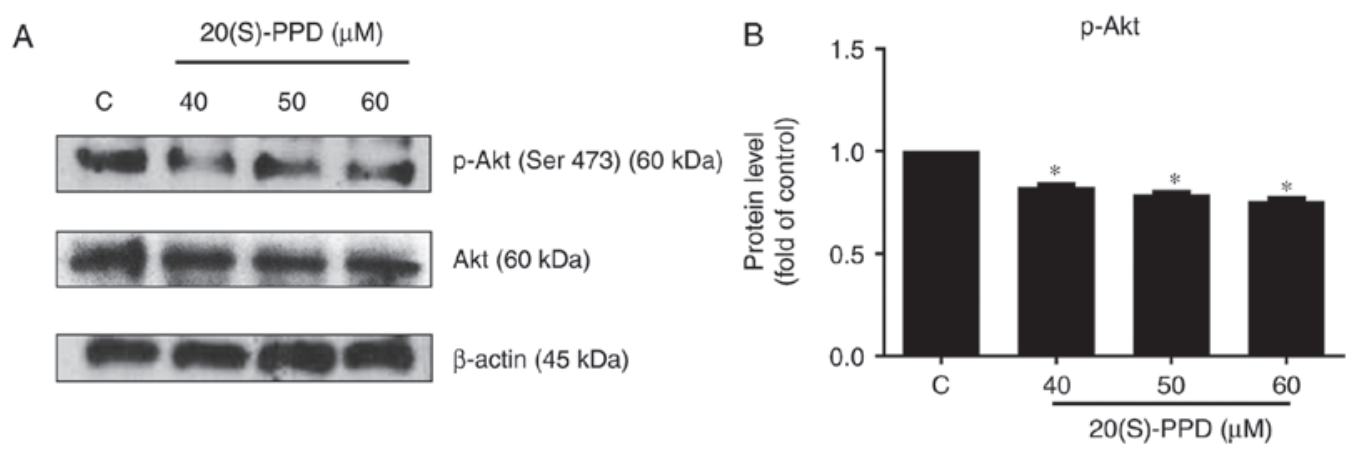

Figure 7. Effects of 20(S)-PPD on the Akt pathway in HepG2 cells. (A) HepG2 cells (4x10 $10^{5}$ per ml) were treated using 0, 40,50 and $60 \mu \mathrm{M}$ of 20 (S)-PPD for $24 \mathrm{~h}$ and the expression of Akt and p-Akt were determined using western blotting. (B) Quantification of western blot analysis for p-Akt. All values are expressed as the mean \pm standard deviation. " $\mathrm{P}<0.05$ vs. the control group. C, control group; 20(S)-PPD, 20(S)-Protopanaxadiol; Akt, protein kinase B; p-, phosphorylated.

belongs to Bcl-2 family and binds to Bcl-xl or Bcl-2 to induce apoptosis (51). Activated Akt phosphorylates Bad and p-Bad is depolymerized with $\mathrm{Bcl}-2$, thus inhibiting the pro-apoptotic effect of Bad $(50,52)$. It has also reported that Bcl-2 and Bax not only act upstream of caspase-3 to regulate it (53) but are also direct substrates of caspase-3 (54). Phosphorylated Bad binds with 14-3-3 protein in the cytoplasm to block the release of Cyt $c$ and inhibit caspase-3 cleavage, thereby inhibiting apoptosis $(55,56)$. In the current study, phosphorylated Akt protein (Ser473) was downregulated following 20(S)-PPD treatment and 20(S)-PPD inhibited the phosphorylation of Akt protein (Ser473). These results indicate that 20(S)-PPD may affect the PI3K/Akt pathway.
In conclusion, the results of the present study indicate that 20(S)-PPD increases the expression of Bax, activates casapase- 9 and -3 , and subsequently, induces apoptosis in human hepatoblastoma HepG2 cells. These results indicate that 20(S)-PPD may be developed as a potential treatment of hepatoblastoma in the future.

\section{Acknowledgements}

The present study was supported by the National Natural Science Foundation of China (grant no. 81173602). The authors wish to thank Xuejin Su for his assistance in flow cytometry data acquisition. 


\section{References}

1. El Asmar A and El Rassi Z: Hepatoblastoma in childhood, long term survival achieved: 2 case reports and literature review. Int J Surg Case Rep 21: 55-58, 2016.

2. Wang YX and Liu H: Adult hepatoblastoma: Systemic review of the English literature. Dig Surg 29: 323-330, 2012.

3. von Schweinitz D: Management of liver tumors in childhood. Semin Pediatr Surg 15: 17-24, 2006.

4. Katzenstein HM, London WB, Douglass EC, Reynolds M, Plaschkes J, Finegold MJ and Bowman LC: Treatment of unresectable and metastatic hepatoblastoma: A pediatric oncology group phase II study. J Clin Oncol 20: 3438-3444, 2002.

5. Reynolds M: Pediatric liver tumors. Semin Surg Oncol 16 $159-172,1999$

6. Brown J, Perilongo G, Shafford E, Keeling J, Pritchard J, Brock P, Dicks-Mireaux C, Phillips A, Vos A and Plaschkes J: Pretreatment prognostic factors for children with hepatoblastoma-results from the International Society of Paediatric Oncology (SIOP) study SIOPEL 1. Eur J Cancer 36: 1418-1425, 2000.

7. Ortega JA, Douglass EC, Feusner JH, Reynolds M, Quinn JJ, Finegold MJ, Haas JE, King DR, Liu-Mares W, Sensel MG and Krailo MD: Randomized comparison of cisplatin/vincristine/fluorouracil and cisplatin/continuous infusion doxorubicin for treatment of pediatric hepatoblastoma: A report from the Children's Cancer Group and the Pediatric Oncology Group J Clin Oncol 18: 2665-2675, 2000.

8. Ikeda H, Matsuyama S and Tanimura M: Association between hepatoblastoma and very low birth weight: A trend or a chance? J Pediatr 130: 557-560, 1997.

9. Kerr JF, Wyllie AH and Currie AR: Apoptosis: A basic biological phenomenon with wide-ranging implications in tissue kinetics Br J Cancer 26: 239-257, 1972.

10. Sgonc R and Gruber J: Apoptosis detection: An overview. Exp Gerontol 33: 525-533, 1998

11. González-Mariscal L, Miranda J, Raya-Sandino A, Dominguez-Calderon A and Cuellar-Perez F: ZO-2, a tight junction protein involved in gene expression, proliferation, apoptosis, and cell size regulation. Ann N Y Acad Sci 1397: 35-53, 2017.

12. Logue SE, Cleary P, Saveljeva S and Samali A: New directions in ER stress-induced cell death. Apoptosis 18: 537-546, 2013.

13. Jia LT, Chen SY and Yang AG: Cancer gene therapy targeting cellular apoptosis machinery. Cancer Treat Rev 38: 868-876, 2012.

14. Muñoz-Pinedo C, Guío-Carrion A, Goldstein JC, Fitzgerald P, Newmeyer DD and Green DR: Different mitochondrial intermembrane space proteins are released during apoptosis in a manner that is coordinately initiated but can vary in duration. Proc Natl Acad Sci USA 103: 11573-11578, 2006.

15. Mane SD, Thoh M, Sharma D, Sandur SK and Naidu KA: Ascorbyl stearate promotes apoptosis through intrinsic mitochondrial pathway in HeLa cancer cells. Anticancer Res 36 6409-6417, 2016.

16. Sun LM, Liu YC, Li W, Liu S, Liu HX, Li LW and Ma R: Nivolumab effectively inhibit platinum-resistant ovarian cancer cells via induction of cell apoptosis and inhibition of ADAM17 expression. Eur Rev Med Pharmacol Sci 21: 1198-1205, 2017.

17. Li X, Yan X, Guo W, Huang X, Huang J, Yu M, Ma Z, Xu Y, Huang S, Li C, et al: Chidamide in FLT3-ITD positive acute myeloid leukemia and the synergistic effect in combination with cytarabine. Biomed Pharmacother 90: 699-704, 2017.

18. Zhang Z, Zhang H, Chen S, Xu Y, Yao A, Liao Q, Han L, Zou Z and Zhang X: Dihydromyricetin induces mitochondria-mediated apoptosis in HepG2 cells through down-regulation of the Akt/Bad pathway. Nutr Res 38: 27-33, 2017.

19. Zhou C, Cheng H, Qin W, Zhang Y, Xiong H, Yang J, Huang H, Wang Y, Chen XZ and Tang J: Pygopus2 inhibits the efficacy of paclitaxel-induced apoptosis and induces multidrug resistance in human glioma cells. Oncotarget 8: 27915-27928, 2017.

20. Xie JT, Wang CZ, Zhang B, Mehendale SR, Li XL, Sun S, Han AH, Du W, He TC and Yuan CS: In vitro and in vivo anticancer effects of American ginseng berry: Exploring representative compounds. Biol Pharm Bull 32: $1552-1558,2009$.

21. Bak DH, Kim HD, Kim YO, Park CG, Han SY and Kim JJ: Neuroprotective effects of 20(S)-protopanaxadiol against glutamate-induced mitochondrial dysfunction in PC12 cells. Int J Mol Med 37: 378-386, 2016.
22. Wang GL, He ZM, Zhu HY, Gao YG, Zhao Y, Yang H and Zhang L: Involvement of serotonergic, noradrenergic and dopaminergic systems in the antidepressant-like effect of ginsenoside $\mathrm{Rb1}$, a major active ingredient of Panax ginseng C.A. Meyer. J Ethnopharmacol 204: 118-124, 2017.

23. Oh SJ, Kim K and Lim CJ: Photoprotective properties of 20(S)-protopanaxatriol, an aglycone of ginseng saponins: Protection from ultraviolet-B radiation-induced oxidative stress in human epidermal keratinocytes. Mol Med Rep 14: 2839-2845, 2016.

24. Oh HA, Kim DE, Choi HJ, Kim NJ and Kim DH: Anti-fatigue Effects of 20(S)-Protopanaxadiol and 20(S)-Protopanaxatriol in mice. Biol Pharm Bull 38: 1415-1419, 2015.

25. Zhang H, Xu HL, Fu WW, Xin Y, Li MW, Wang SJ, Yu XF and Sui DY: 20(S)-Protopanaxadiol induces human breast cancer MCF-7 apoptosis through a caspase-mediated pathway. Asian Pac J Cancer Prev 15: 7919-7923, 2014.

26. Zhang YL, Zhang R, Xu HL, Yu XF, Qu SC and Sui DY: 20(S)-protopanaxadiol triggers mitochondrial-mediated apoptosis in human lung adenocarcinoma A549 cells via inhibiting the PI3K/Akt signaling pathway. Am J Chin Med 41: 1137-1152, 2013.

27. Ben-Eltriki M, Deb S, Adomat $\mathrm{H}$ and Tomlinson Guns ES: Calcitriol and 20(S)-protopanaxadiol synergistically inhibit growth and induce apoptosis in human prostate cancer cells. J Steroid Biochem Mol Biol 158: 207-219, 2016.

28. Cao B, Qi Y, Yang Y, Liu X, Xu D, Guo W, Zhan Y, Xiong Z, Zhang A, Wang AR, et al: 20(S)-protopanaxadiol inhibition of progression and growth of castration-resistant prostate cancer. PLoS One 9: e111201, 2014

29. Yasuhara S, Zhu Y, Matsui T, Tipirneni N, Yasuhara Y, Kaneki M, Rosenzweig A and Martyn JA: Comparison of comet assay, electron microscopy, and flow cytometry for detection of apoptosis. J Histochem Cytochem 51: 873-885, 2003.

30. Hail N Jr, Carter BZ, Konopleva M and Andreeff M: Apoptosis effector mechanisms: A requiem performed in different keys. Apoptosis 11: 889-904, 2006.

31. Van Ummersen L, Binger K, Volkman J, Marnocha R, Tutsch K, Kolesar J, Arzoomanian R, Alberti D and Wilding G: A phase I trial of perifosine (NSC 639966) on a loading dose/maintenance dose schedule in patients with advanced cancer. Clin Cancer Res 10: 7450-7456, 2004.

32. Kim W, Seong J, An JH and Oh HJ: Enhancement of tumor radioresponse by wortmannin in $\mathrm{C} 3 \mathrm{H} / \mathrm{HeJ}$ hepatocarcinoma. J Radiat Res 48: 187-195, 2007.

33. Park HH: Structural features of caspase-activating complexes. Int J Mol Sci 13: 4807-4818, 2012

34. Ping P and Murphy E: Role of p38 mitogen-activated protein kinases in preconditioning: a detrimental factor or a protective kinase? Circ Res 86: 921-922, 2000.

35. Häcker G and Paschen SA: Therapeutic targets in the mitochondrial apoptotic pathway. Expert Opin Ther Targets 11: 515-526, 2007.

36. Cryns V and Yuan J: Proteases to die for. Genes Dev 12: 1551-1570, 1998.

37. Penninger JM and Kroemer G: Mitochondria, AIF and caspases-rivaling for cell death execution. Nat Cell Biol 5: 97-99, 2003.

38. Herr I and Debatin KM: Cellular stress response and apoptosis in cancer therapy. Blood 98: 2603-2614, 2001.

39. Chawla-Sarkar M, Leaman DW and Borden EC: Preferential induction of apoptosis by interferon (IFN)-beta compared with IFN-alpha2: Correlation with TRAIL/Apo2 L induction in melanoma cell lines. Clin Cancer Res 7: 1821-1831, 2001.

40. Decuypere JP, Parys JB and Bultynck G: Regulation of the autophagic bcl-2/beclin 1 interaction. Cells 1: 284-312, 2012.

41. Kelly PN and Strasser A: The role of Bcl-2 and its pro-survival relatives in tumourigenesis and cancer therapy. Cell Death Differ 18: 1414-1424, 2011.

42. Ellerby LM, Ellerby HM, Park SM, Holleran AL, Murphy AN, Fiskum G, Kane DJ, Testa MP, Kayalar C and Bredesen DE: Shift of the cellular oxidation-reduction potential in neural cells expressing Bcl-2. J Neurochem 67: 1259-1267, 1996.

43. Eleawa SM, Alkhateeb MA, Alhashem FH, Bin-Jaliah I, Sakr HF, Elrefaey HM, Elkarib AO, Alessa RM, Haidara MA, Shatoor AS and Khalil MA: Resveratrol reverses cadmium chloride-induced testicular damage and subfertility by downregulating p53 and Bax and upregulating gonadotropins and $\mathrm{Bcl}-2$ gene expression. J Reprod Dev 60: 115-127, 2014. 
44. Hokin MR and Hokin LE: Enzyme secretion and the incorporation of P32 into phospholipides of pancreas slices. J Biol Chem 203: 967-977, 1953.

45. Streb H, Irvine RF, Berridge MJ and Schulz I: Release of Ca2+ from a nonmitochondrial intracellular store in pancreatic acinar cells by inositol-1,4,5-trisphosphate. Nature 306: 67-69, 1983.

46. Nishizuka Y: Studies and perspectives of protein kinase C. Science 233: 305-312, 1986.

47. Samuels Y, Wang Z, Bardelli A, Silliman N, Ptak J, Szabo S, Yan H, Gazdar A, Powell SM, Riggins GJ, et al: High frequency of mutations of the PIK3CA gene in human cancers. Science 304: 554, 2004

48. Osaki M, Oshimura M and Ito H: PI3K-Akt pathway: Its functions and alterations in human cancer. Apoptosis 9: 667-676, 2004.

49. Nicholson KM and Anderson NG: The protein kinase B/Akt signalling pathway in human malignancy. Cell Signal 14: 381-395, 2002.

50. Hers I, Vincent EE and Tavaré JM: Akt signalling in health and disease. Cell Signal 23: 1515-1527, 2011.

51. Zha J, Harada H, Yang E, Jockel J and Korsmeyer SJ: Serine phosphorylation of death agonist BAD in response to survival factor results in binding to 14-3-3 not BCL-X(L). Cell 87: 619-628, 1996.

52. Yang E, Zha J, Jockel J, Boise LH, Thompson CB and Korsmeyer SJ: Bad, a heterodimeric partner for Bcl-XL and Bcl-2, displaces Bax and promotes cell death. Cell 80: 285-291, 1995.
53. Zhao H, Yenari MA, Cheng D, Sapolsky RM and Steinberg GK: $\mathrm{Bcl}-2$ overexpression protects against neuron loss within the ischemic margin following experimental stroke and inhibits cytochrome $\mathrm{c}$ translocation and caspase-3 activity. J Neurochem 85: 1026-1036, 2003.

54. Kirsch DG, Doseff A, Chau BN, Lim DS, de Souza-Pinto NC, Hansford R, Kastan MB, Lazebnik YA and Hardwick JM: Caspase-3-dependent cleavage of $\mathrm{Bcl}-2$ promotes release of cytochrome c. J Biol Chem 274: 21155-21161, 1999.

55. Song G, Ouyang G and Bao S: The activation of Akt/PKB signaling pathway and cell survival. J Cell Mol Med 9: 59-71, 2005.

56. Datta SR, Ranger AM, Lin MZ, Sturgill JF, Ma YC, Cowan CW, Dikkes P, Korsmeyer SJ and Greenberg ME: Survival factor-mediated BAD phosphorylation raises the mitochondrial threshold for apoptosis. Dev Cell 3: 631-643, 2002.

This work is licensed under a Creative Commons Attribution-NonCommercial-NoDerivatives 4.0 International (CC BY-NC-ND 4.0) License. 